\title{
Filler Migration and Granuloma Formation After Gluteal Augmentation with Free- silicone Injections
}

Alexander Leyva ${ }^{1}$, Tri Tran ${ }^{2}$, Andrew T. Cibulas ${ }^{3}$, David R. Warden IV ${ }^{3}$, Franklin J. Danger ${ }^{3}$, Kurt Scherer ${ }^{4}$, Christopher Wasyliw ${ }^{4}$

1. Radiology, Florida Hospital, Orlando, USA 2. Undergraduate Studies, University of Central Florida, Orlando, USA 3. Radiology, Florida Hospital-Orlando, Orlando, USA 4. Diagnostic Radiology, Florida Hospital-Orlando, Orlando, USA

$\square$ Corresponding author: Alexander Leyva, alexander.leyva.md@flhosp.org Disclosures can be found in Additional Information at the end of the article

\section{Abstract}

Gluteal augmentation may be performed using a variety of techniques, including implantbased, autologous fat grafting, local flaps, impermanent filler injection, or, as in this case, by way of permanent filler injection with free-silicone. Of these, free-silicone injections carry one of the highest complication rates, specifically regarding migration of the filler material from the native injection site and induction of painful reactive soft tissue changes at the new filler location. A radiologist providing this diagnosis may assist the clinician, who often cannot obtain a history of illicit silicone injection for gluteal augmentation unless the suspicion is raised. Presented here is a case of painful filler migration to the knee with granuloma formation after free-silicone gluteal injection.

Categories: Plastic Surgery, Radiology, Orthopedics

Keywords: free silicone, gluteal augmentation, filler migration, silicone injections, granulomas, liquid silicone, adulterated silicone, silicone migration, granuloma formation

\section{Introduction}

Gluteal augmentation has become increasingly popular as a means of enhancing physical appearance. The most popular methods involve implant-based techniques, as well as autologous fat injection. Additional, less common techniques include local fat or muscle flaps, resorbable dermal filler injection using hyaluronic acid gel, and permanent filler injection using free liquid silicone [1, 2]. Free-silicone injection is an attractive option to many patients due to its relative low cost $[3,4]$. However, many cases of complication development due to the use of

Received 08/31/2018 Review began 09/03/2018 Review ended 09/10/2018 Published 09/13/2018

\section{(c) Copyright 2018}

Leyva et al. This is an open access article distributed under the terms of the Creative Commons Attribution License CC-BY 3.0., which permits unrestricted use, distribution, and reproduction in any medium, provided the original author and source are credited. silicone for buttock, and similarly breast, enhancement have been reported. Rates of complications are especially high when adulterated silicone and large volumes are used, which often contains oil-based byproducts along with other often poorly-tolerated impurities [5-8]. Of the possible complications, filler migration with resultant granuloma formation is relatively common and thus important to recognize. Even when pure medical-grade silicone is used, granuloma formation can occur in up to $20 \%$ of patients, especially with higher volume injections $[9,10]$.

\section{Case Presentation}

A 28-year-old woman with a history of uterine malignancy, deep vein thrombosis, and hepatitis $\mathrm{B}$, who had been recently admitted as an inpatient for management of renal calculi 


\section{Cureus}

presented with left knee pain. A magnetic resonance imaging (MRI) scan of the left knee was subsequently ordered by the patient's clinician. Prior to prescribing an MRI of the left knee, the patient had undergone a recent computerized tomography (CT) scan of the abdomen and pelvis, which had demonstrated numerous partially calcified granulomas in the gluteal subcutaneous tissues bilaterally (Figure 1). Additionally, a recent chest CT demonstrated similar findings of prior free-silicone injections within the bilateral breasts and surrounding granulomatous change (Figure 2). MRI of the left knee revealed scattered, small circumscribed areas of signal abnormality in the posterior distal thigh, as well as within the subcutaneous tissues and fascia of the popliteal fossa. These round structures were low in signal on proton density, T1, and T2-weighted sequences (Figure 3).

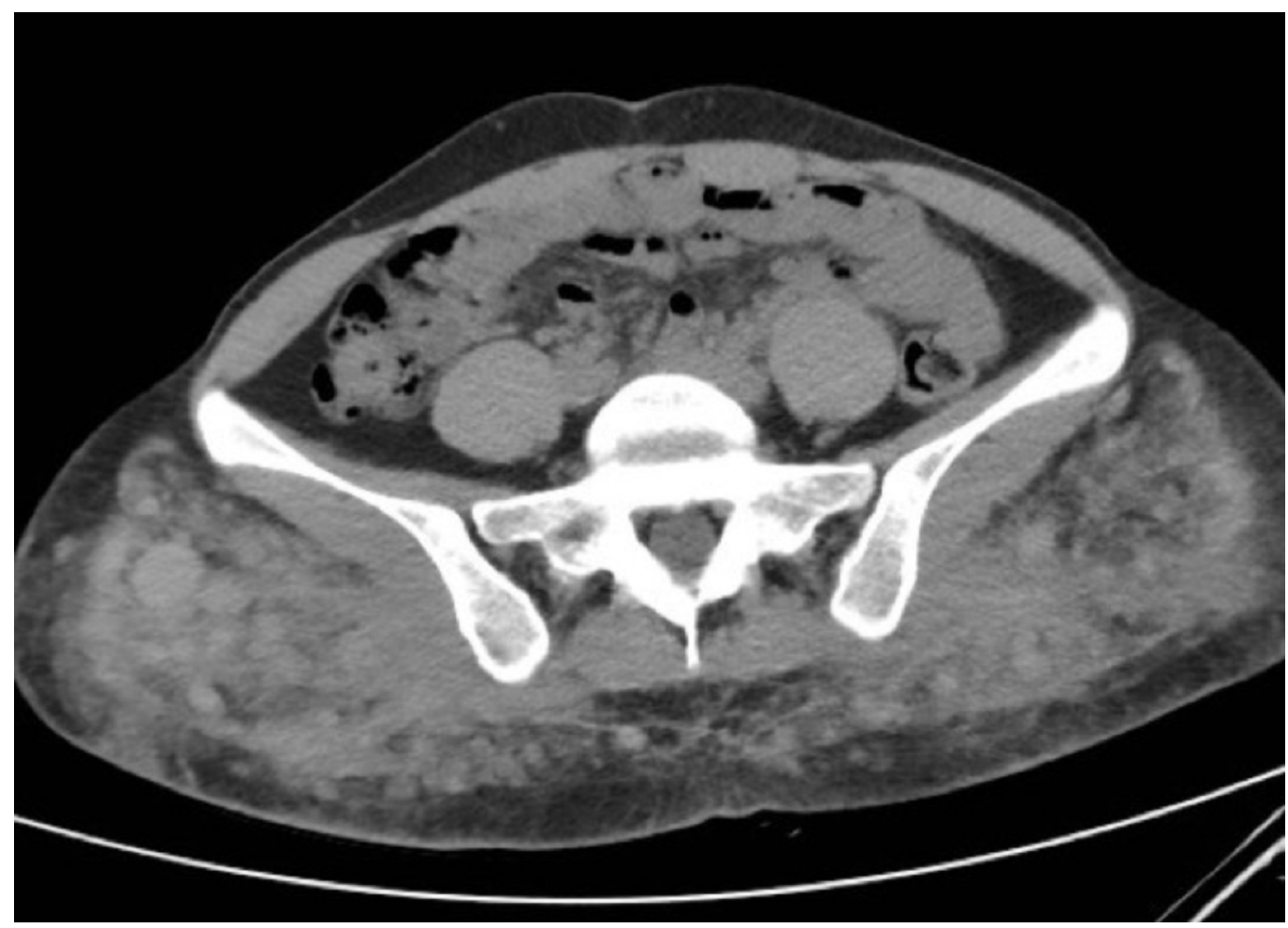

\section{FIGURE 1: CT Abdomen/Pelvis}

Axial CT image of the pelvis demonstrates sites of prior subcutaneous gluteal free-silicone injection with associated reactive soft tissue changes, including granuloma formation.
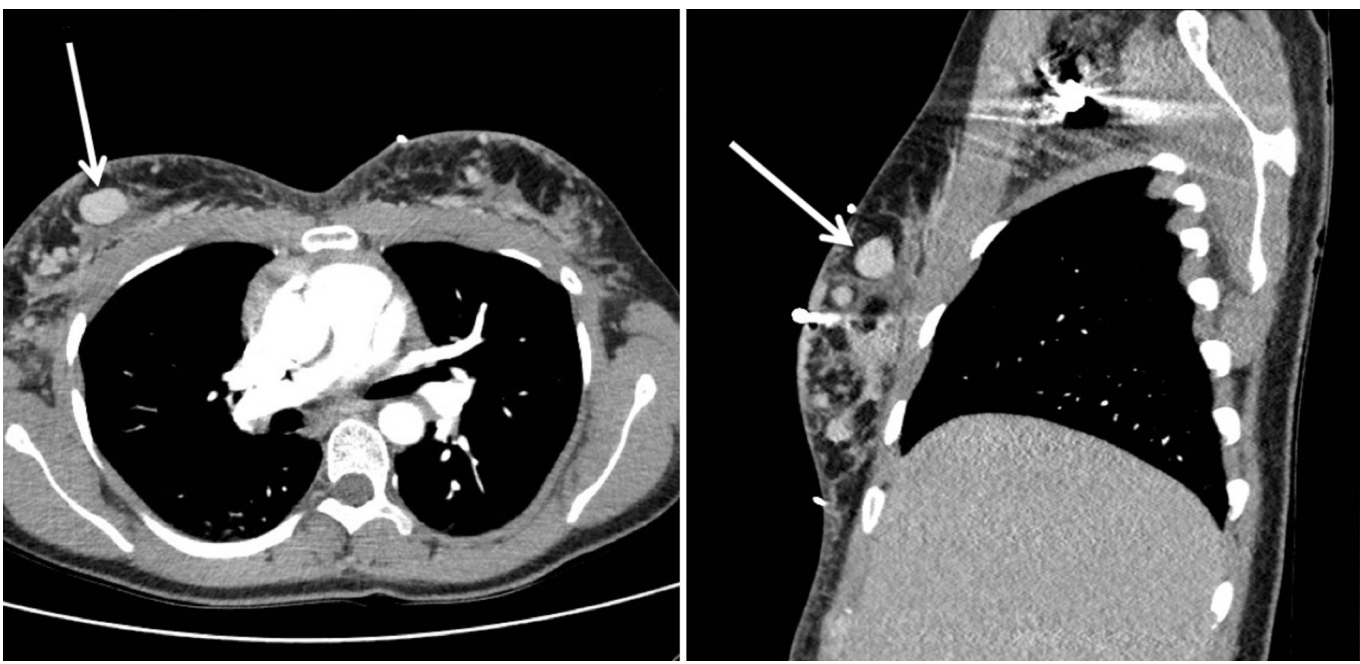


\section{Cureus}

\section{FIGURE 2: CT Chest}

Axial (left) and sagittal (right) contrast-enhanced CT images of the chest demonstrate bilateral areas of prior free-silicone injection with surrounding granulomatous change. The largest globule of free silicone is visualized within the right breast (arrows).
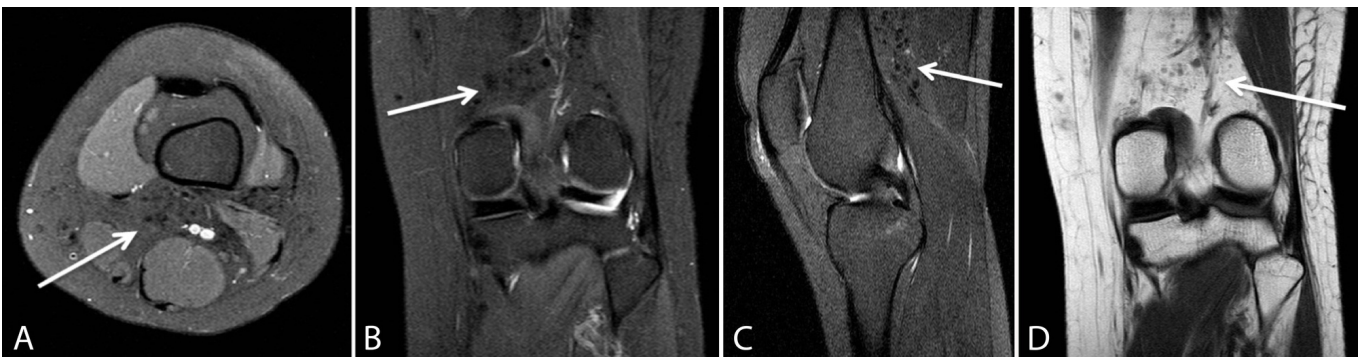

\section{FIGURE 3: MRI Left Knee}

Axial proton-density $(A)$, coronal proton-density $(B)$, sagittal T2-weighted $(C)$, and coronal T1weighted $(D)$ MR images of the left knee demonstrate translocated free-silicone and reactive granuloma formation (arrows) within the posterior knee.

\section{Discussion}

Silicone is a substance with a controversial history. It belongs to a family of synthetic polymers comprised of the element silicon, of which the liquid form was first used for breast enhancement in the United States in 1963 [4, 9]. Due to increasing rates of associated complications, Nevada became the first state to criminalize the use of free-silicone in 1975 [4]. Almost two decades later, in 1992, after implant-based methods of breast augmentation had been developed, the U.S. Food and Drug Administration (FDA) temporarily banned the use of silicone breast implants to conduct studies on its safety, eventually lifting the ban in 2006 [10]. Today, free-silicone injection is only approved for ophthalmic use in the setting of retinal detachment [4].

Although safety remains a topic of debate, silicone-related procedures continue to be performed routinely, and often illegally, in many countries for cosmetic purposes [4, 10]. The patient presented here had obtained illicit free-silicone injections for breast and buttock augmentation. Given the illicit nature of this procedure, the patient initially failed to disclose this information. In cases with such limited available history, it may be difficult for clinicians to effectively diagnose conditions leading to painful granuloma formation. Imaging findings, such as those previously discussed involving various sites with multi-focal reactive soft tissue changes and granuloma formation, offer clues to the final diagnosis. As a result, the practicing radiologist may assist the clinician in considering this diagnosis by evaluating for the typical CT and MR imaging features previously outlined.

The final diagnosis for this case included granuloma formation in the posterior thigh and popliteal fossa with caudal migration of free-silicone to the left knee. Findings on provided MR images, however, are not specific for the diagnosis. In conjunction with the aforementioned CT imaging features of the pelvis and chest, demonstrating probable injection sites with surrounding reactive soft tissue change, the final radiologic diagnosis may be suggested. 


\section{Conclusions}

This case demonstrates complications from an unusual form of gluteal and breast augmentation by free-silicone injection. Since patients do not typically disclose undergoing illicit procedures, the practicing radiologist may assist the clinician in proposing the diagnosis when the appropriate imaging findings are present.

\section{Additional Information}

\section{Disclosures}

Human subjects: Consent was obtained by all participants in this study. Conflicts of interest: In compliance with the ICMJE uniform disclosure form, all authors declare the following:

Payment/services info: All authors have declared that no financial support was received from any organization for the submitted work. Financial relationships: All authors have declared that they have no financial relationships at present or within the previous three years with any organizations that might have an interest in the submitted work. Other relationships: All authors have declared that there are no other relationships or activities that could appear to have influenced the submitted work.

\section{References}

1. Yahyavi-Firouz-Abadi N, Menias CO, Bhalla S, Siegel C, Gayer G, Katz DS: Imaging of cosmetic plastic procedures and implants in the body and their potential complications. AJR Am J Roentgenol. 2015, 204:707-15. 10.2214/AJR.14.13516

2. Oranges CM, Tremp M, di Summa PG, Haug M, Kalbermatten DF, Harder Y, Schaefer DJ: Gluteal augmentation techniques: a comprehensive literature review . Aesthet Surg J. 2017, 37:560-569. 10.1093/asj/sjw240

3. Singh M, Solomon IH, Calderwood MS, Talbot SG: Silicone-induced granuloma after buttock augmentation. Plast Reconstr Surg Glob Open. 2016, 4:624. 10.1097/GOX.0000000000000618

4. Narins RS, Beer K: Liquid injectable silicone: a review of its history, immunology, technical considerations, complications, and potential. Plast Reconstr Surg. 2006, 118:77S-84S. 10.1097/01.prs.0000234919.25096.67

5. Lopiccolo MC, Workman BJ, Chaffins ML, Kerr HA: Silicone granulomas after soft-tissue augmentation of the buttocks: a case report and review of management. Dermatol Surg. 2011, 37:720-5. 10.1111/j.1524-4725.2011.01978.x

6. Wosnitzer B, Mirtcheva R: Silicone granulomas following free silicone gluteal augmentation . Radiol Case Rep. 2011, 6:491-510. 10.2484/rcr.v6i1.491

7. Nasseri E: Gluteal augmentation with liquid silicone of unknown purity causes granulomas in an adult female: case report and review of the literature. J Cutan Med Surg. 2015, 20:72-9. $10.1177 / 1203475415598065$

8. Leonardi NR, Compoginis JM, Luce EA: Illicit cosmetic silicone injection: a recent reiteration of history. Ann Plast Surg. 2016, 77:485-90. 10.1097/SAP.0000000000000756

9. Chasan PE: The history of injectable silicone fluids for soft-tissue augmentation . Plast Reconstr Surg. 2007, 120:2034-40. 10.1097/01.prs.0000267580.92163.33

10. Hajdu SD, Agmon-Levin N, Shoenfeld Y: Silicone and autoimmunity. Eur J Clin Invest. 2011, 41:203-11. 10.1111/j.1365-2362.2010.02389.x 